\title{
Hexane extract from Sargassum serratifolium inhibits the cell proliferation and metastatic ability of human glioblastoma U87MG cells
}

\author{
CHANG-WON KANG ${ }^{1 *}$, MIN-SEOK PARK ${ }^{1 *}$, NAN-HEE KIM ${ }^{1}$, JI-HYUN LEE $^{1}$, \\ CHUL-WOONG OH ${ }^{2}$, HYEUNG-RAK KIM ${ }^{3}$ and GUN-DO KIM ${ }^{1}$ \\ ${ }^{1}$ Department of Microbiology, College of Natural Science, and Departments of ${ }^{2}$ Marine Biology and \\ ${ }^{3}$ Food Science and Nutrition, College of Fisheries Science, Pukyong National University, Busan 608-737, Republic of Korea
}

Received May 20, 2015; Accepted June 29, 2015

DOI: 10.3892/or.2015.4222

\begin{abstract}
The present study is the first to demonstrate the anticancer effects of a hexane extract from the brown algae Sargassum serratifolium (HES) on human cancer cell lines, including glioblastoma U87MG, cervical cancer HeLa and gastric cancer MKN-28 cells, as well as liver cancer SK-HEP 1 cells. Among these cancer cell lines, U87MG cells were most sensitive to the cell death induced by HES. HES exhibited a cytotoxic effect on U87MG cells at concentrations of $14-16 \mu \mathrm{g} / \mathrm{ml}$, yet an effect was not observed in human embryonic kidney HEK293 cells. The antiproliferative effects of HES were regulated by inhibition of the MAPK/ERK signaling pathway which plays a pivotal role in the proliferation of glioblastoma U87MG cells. In addition, treatment with HES led to cell morphological changes and cell cytoskeleton degradation through regulation of actin dynamic signaling. Furthermore, migration and invasion of the U87MG cells were inhibited by HES via suppression of matrix metalloproteinase (MMP)-2 and -9 expression. Thus, our results suggest that HES is a potential therapeutic agent which has anticancer effects on glioblastoma.
\end{abstract}

\section{Introduction}

Human glioblastoma is one of the most common and malignant tumors, that originates from glial cells (1). Glioblastoma is characterized by rapid invasion and distant migration (2). Current therapeutic strategies for glioblastoma include

Correspondence to: Professor Gun-Do Kim, Department of Microbiology, College of Natural Science, Pukyong National University, Busan 608-737, Republic of Korea

E-mail: gundokim@pknu.ac.kr

*Contributed equally

Key words: antiproliferation, cell cytoskeleton, glioblastoma, metastasis, Sargassum serratifolium surgery, radiation therapy and chemotherapy. However, the median survival of glioblastoma patients is extremely poor (3).

Mitogen-activated protein kinase (MAPK) signaling regulates diverse cellular functions, such as cell proliferation, the cell cycle, cell survival, angiogenesis and cell migration (4). The MAPK cascade is initiated by Ras activation which is regulated by receptor tyrosine kinases at the cell surface. Ras activation recruits $\mathrm{C}$-Raf to the cell membrane, processing the phosphorylation of multiple co-factors (5). Downstream of the C-Raf proteins are MEK1 and MEK2, a dual serine/threonine and tyrosine kinase (6). MEK further transmits signals to extracellular regulated serine/threonine kinases (ERK), comprised of ERK1 and ERK2 (7). The cellular functions of ERK play diverse roles in the regulation of cell proliferation, survival, mitosis and migration (8).

The cytoskeleton plays pivotal roles in various signaling pathways related to cellular adhesion, cytokinesis, cell survival and transcriptional processes (9). Particularly, reorganization of the actin cytoskeleton is essential for the migration and metastasis of malignant tumors. Actin reorganization is regulated by Rac, the Wiskott-Aldrich syndrome protein (WASP) family and actin-related protein (Arp) (10). Rac is a Ras-related GTP binding protein that controls assembly and disassembly of actin cytoskeleton by transducing extracellular chemoattractive signals to downstream effectors such as WASP family verprolin-homologous protein-2 (WAVE-2) and Arp-2. WAVE-2 activates the Arp2/3 complex through their binding and consequently the Arp $2 / 3$ complex locates to actin filament branches and crosslinks into a branching network (11). In addition, they play a functional role in lamellipodium formation that is related to the invasion and metastasis of malignant tumors $(12,13)$.

Metastasis is a mechanism by which new tumors form in distant tissues from a primary tumor. Cell migration and invasion are required for cancer metastasis. Invasion is induced by matrix metalloproteinases (MMPs) that induce degradation of the extracellular matrix (ECM) and basement membrane $(14,15)$. Thus, inhibition of MMPs is considered to be a therapeutic strategy for tumor metastasis.

Sargassum (Sargassaceae, Fucales) is a genus of brown seaweed that is found in all the oceans. Previous research on 
Sargassum spp. extracts have been reported to exhibit anticancer, antibacterial, antifungal, antiviral, anti-inflammatory, anticoagulant, antioxidant, hepatoprotective and neuroprotective activities (16). However, the pharmacological effect of extracts from Sargassum serratifolium (S. serratifolium) has not been thoroughly studied in glioblastoma. Therefore, the present study aimed to investigate the anticancer effects of an extract from $S$. serratifolium on U87MG glioblastoma cells.

\section{Materials and methods}

Preparation of the hexane extracts. S. serratifolium was collected from the coast of Busan, Korea, in April 2013. Taxonomic identification was confirmed by an algal taxonomist (C.K. Choi) at the Department of Ecological Engineering, Pukyong National University, Korea. The seaweed was rinsed in tap water to remove salt and air-dried under sunlight for 3 days. The dried powder $(1.5 \mathrm{~kg})$ of $S$. serratifolium underwent extraction three times with $96 \%(\mathrm{v} / \mathrm{v})$ ethanol $(\mathrm{EtOH})$ for $3 \mathrm{~h}$ at $70^{\circ} \mathrm{C}$. The combined extracts were concentrated under reduced pressure to obtain the $\mathrm{EtOH}$ extract. For further fractionation of the EtOH extract, the extract was resuspended in water:EtOH (9:1) and partitioned successively with $n$-hexane and ethyl acetate. The $n$-hexane extract, which showed the highest cell cytotoxic activities against U87MG cells, was maintained at $-20^{\circ} \mathrm{C}$ and was used for the present study.

Cell culture. Human glioblastoma cancer U87MG, human cervical cancer HeLa, human gastric cancer MKN-28 and human liver cancer SK-HEP 1 cells as well as human embryonic kidney HEK-293 cells, were obtained from the American Tissue Culture Collection (ATCC; Manassas, VA, USA). U87MG and SK-HEP 1 cells were incubated with minimum essential medium (MEM), MKN-28 cells were incubated with RPMI-1640 medium, and HeLa and HEK-293 cells were incubated in Dulbecco's modified Eagle's medium (DMEM) supplemented with $10 \%$ fetal bovine serum (FBS), $1 \%$ penicillin-streptomycin (PAA Laboratories $\mathrm{GmbH}$, Pasching, Austria). The cells were cultured in a $5 \% \mathrm{CO}_{2}$ incubator (binder) at $37^{\circ} \mathrm{C}$ in a humidified atmosphere. The culture was sub-cultured every 3 to 4 days and routinely checked under an inverted microscope for any contamination.

Cell cytotoxicity and morphology. The effects of the extracts of Sargassum serratifolium on cell viability were evaluated by WST-1 assay, based on the reduction of the number of metabolically active cells, and the results are expressed as a percentage of the control. Cells were seeded in 96-well microplates at a density of $1 \times 10^{4}$ cells/well and were cultured for $24 \mathrm{~h}$. After $24 \mathrm{~h}$, the cells were treated with the extracts at various concentrations and incubated for 12 and $24 \mathrm{~h}$. Then, the media was replaced and 2-(4-iodophenyl)-3-(4-nitrophenyl)-5-(2,4disulforphenyl)-2H-tetrazolium, monosodium salt (WST-1 solution) was added to each well at $10 \mu \mathrm{l}$, and the cells were incubated at $37^{\circ} \mathrm{C}$ for $3 \mathrm{~h}$. Finally the optical density (OD) was measured with an ELISA reader (Molecular Devices, Silicon Valley, CA, USA) at $460 \mathrm{~nm}$. The cytotoxic activity of the extract was expressed as an $\mathrm{IC}_{50}$ value, which is the concentration of the extract that caused $50 \%$ cell death. The extract with an $\mathrm{IC}_{50}$ value $\leq 16 \mu \mathrm{g} / \mathrm{ml}$ was considered active.
Dimethylsulfoxide (DMSO) was used to dilute the extracts and the final concentration of DMSO in each well was not in excess of $0.5 \%(\mathrm{v} / \mathrm{v})$. No adverse effect due to the presence of DMSO was observed.

Protein extraction and western blot analysis. U87MG cells were treated with Sargassum serratifolium. The treated cells were washed with ice-cold $1 \mathrm{X}$ phosphate-buffered saline (PBS) and collected in lysis buffer [(50 mM Tris-Cl (pH 7.5), $150 \mathrm{mM} \mathrm{NaCl}, 1 \mathrm{mM}$ DTT, $0.5 \%$ NP-40, $1 \%$ Triton X-100, $1 \%$ deoxycholate, $0.1 \% \mathrm{SDS}]$ and a proteinase inhibitor cocktail [PMSF, EDTA, aptotinin, leupeptin, prostatin A (Intron Biotechnology, Gyeonggi, Korea)] on ice. After incubation on ice for $30 \mathrm{~min}$, the insoluble materials were removed by centrifugation at $14,000 \mathrm{rpm}$ for $20 \mathrm{~min}$. Protein contents of the cell lysates were determined by a protein quantification kit (Commasie Brilliant Blue solution ${ }^{\circledR}$ ) (Dojindo Molecular Technologies, Rockville, MD, USA) with bovine serum albumin (BSA) as a standard. The absorbance was determined at $595 \mathrm{~nm}$. An aliquot from each sample was boiled for $5 \mathrm{~min}$ and then resolved by $12 \% \mathrm{SDS}$-polyacrylamide gel electrophoresis (SDS-PAGE). Then, the proteins were electrotransferred to a nitrocellulose membrane (Pall Life Sciences, Pensacola, FL, USA) and blocked in PBST buffer $\left(135 \mu \mathrm{M} \mathrm{NaCl}, 2.7 \mathrm{mM} \mathrm{KCl}, 4.3 \mathrm{mM} \mathrm{NaPO}_{4}, 1.4 \mathrm{mM} \mathrm{KH}_{2} \mathrm{PO}_{4}\right.$ and $0.5 \%$ Tween-20) containing $5 \%$ non-fat milk (w/v). After blocking, the membranes were then incubated with primary antibodies against GAPDH, integrin $\beta 1, \mathrm{Rac1} / 2 / 3$, Ras, PI3K p110 $\alpha$, WAVE-2, Arp-2, MMP-2, MMP-9, phospho-C-Raf ${ }^{\mathrm{Ser} 338}$, phospho-MEK $1 / 2^{\text {Ser217/221, phospho- }}$ ERK $1 / 2^{\mathrm{Thr} 202 / \mathrm{Tyr} 204}$ overnight at $4^{\circ} \mathrm{C}$. The membranes were next incubated with HRP-conjugated secondary antibodies (Cell Signaling Technology) for $60 \mathrm{~min}$. All membranes were visualized using West Save Gold ECL (AbFrontier) and exposed to Hyperfilm (GE Healthcare). GAPDH was used as a loading control.

Wound healing assay. U87MG cells $\left(5.0 \times 10^{5}\right.$ cells/well) were seeded in the chamber of an Ibidi culture insert (Ibidi $\mathrm{GmbH}$, Martinsried, Germany) consisting of two reservoirs separated by a $500 \mu \mathrm{m}$ well and incubated at $37^{\circ} \mathrm{C}$ in an atmosphere of $5 \% \mathrm{CO}_{2}$ for $24 \mathrm{~h}$. After incubation, the inserts were gently removed, and the cells were cultured with medium to facilitate cell migration. Cell migration was recorded by phase contrast microscopy over a time course of $2 \mathrm{~h}$ following treatment with the $S$. serratifolium extract. On-line based Wimasis image analysis was used to carry out quantitative analysis of the cell migration.

Cell invasion assay. The invasion of the tumor cells was assessed in Matrigel-coated Transwell chambers with a $6.5-\mathrm{mm}$ polyvinyl/pyrolidone-free polycarbonate filter with $8-\mu \mathrm{m}$ pore size (Corning Life Sciences) as previously described (17). The U87MG cells $\left(5 \times 10^{4}\right.$ cells/well and test compounds at different concentrations were suspended in $100 \mu \mathrm{l}$ of serum-free medium and placed in the upper Transwell chamber and incubation was carried out for $24 \mathrm{~h}$ at $37^{\circ} \mathrm{C}$. Then, the cells on the upper surface of the filter were completely wiped away with a cotton swab, and the cells on the lower surface were lysed with $4 \%$ formaldehyde and stained with crystal violet. After staining, 

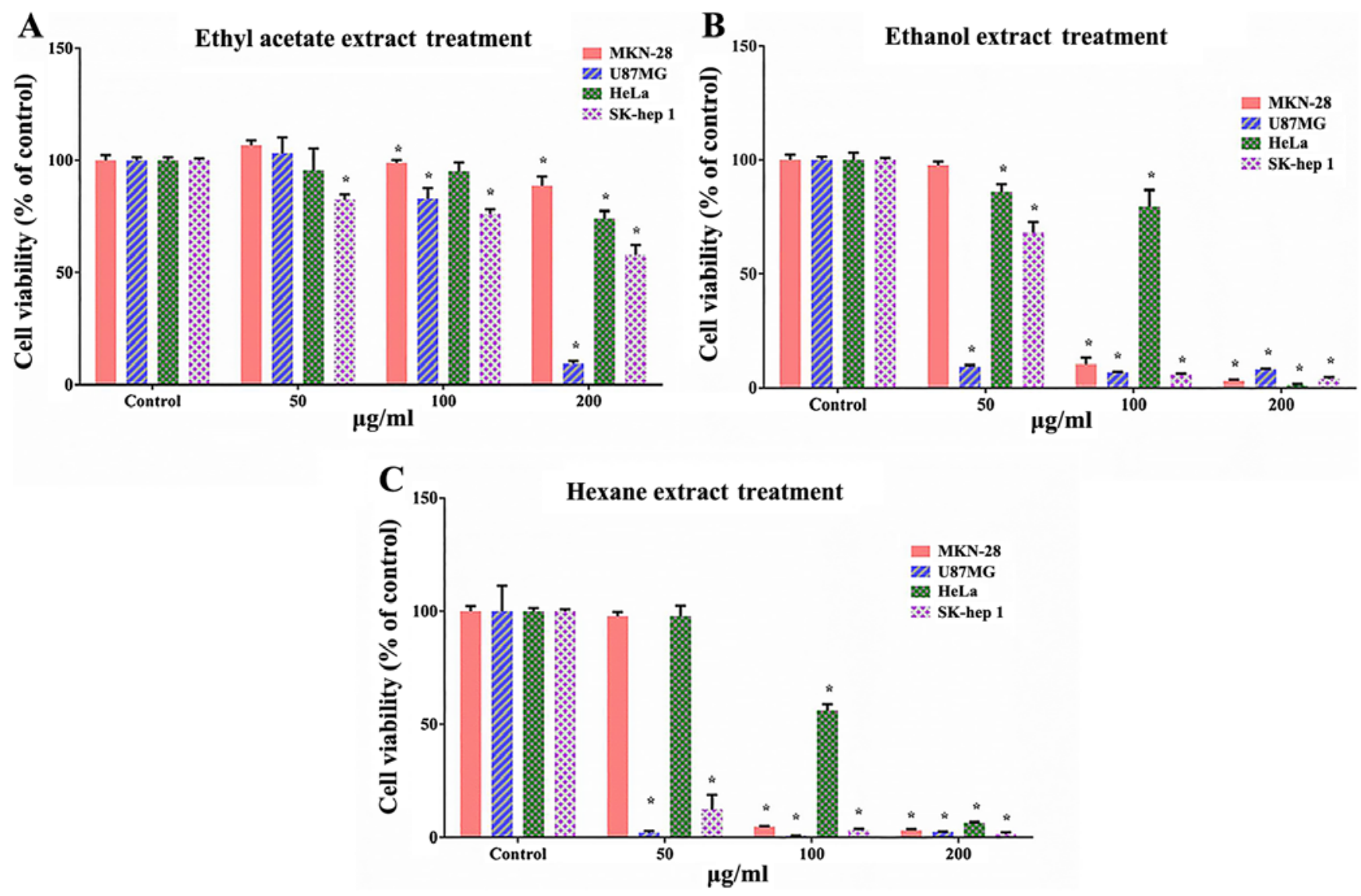

Figure 1. Antiproliferative effects of three extracts from S. serratifolium in human cell lines, including U87MG, MKN-28, HeL, SK-HEP 1 and HEK-293. Cells were treated with the indicated concentrations of (A) ethyl acetate, (B) ethanol and (C) hexane extracts from S. serratifolium for $24 \mathrm{~h}$, and cell survival was assessed by WST-1 assay. Each bar represents the mean $\pm \mathrm{SD}, \mathrm{n}=3$. ${ }^{*} \mathrm{p}<0.001$, significant difference from the control by ANOVA.

cells on the lower surface were lysed with $2 \%$ SDS for $1 \mathrm{~h}$ and the lysate was measured using a microplate reader at $570 \mathrm{~nm}$.

Immunofluorescence. Cultured U87MG cells on a cover glass-bottom dish were incubated for $30 \mathrm{~min}$ with $10 \mu \mathrm{g} / \mathrm{ml}$ HES. For this, the cells were pre-treated with $1 \mu \mathrm{g} / \mathrm{ml}$ DAPI for $20 \mathrm{~min}$ at $37^{\circ} \mathrm{C}$, then fixed with $4 \%$ formaldehyde (Junsei Chemical Co., Ltd., Japan) for $15 \mathrm{~min}$ at $25^{\circ} \mathrm{C}$ and blocked for $1 \mathrm{~h}$ in a blocking solution, including 5\% mouse and rabbit normal serum (Santa Cruz Biotechnology, Inc.) with 0.3\% Triton X-100 (Sigma-Aldrich, St. Louis, MO, USA). Fixed and blocked cells were incubated with the primary antibodies $\left(\beta\right.$-actin, phospho-ERK1/2 ${ }^{\text {Thr202/Tyr204 }}$ ) for $3 \mathrm{~h}$ and washed three times with PBS buffer. After washing, the cells were treated with $0.1 \mu \mathrm{g} / \mathrm{ml}$ of anti-mouse $\mathrm{IgG}(\mathrm{H}+\mathrm{L}), \mathrm{F}\left(\mathrm{ab}^{\prime}\right)_{2}$ fragment (Alexa Fluor ${ }^{\circledast}$ 555-conjugated) and anti-rabbit IgG $(\mathrm{H}+\mathrm{L})$, $\mathrm{F}\left(\mathrm{ab}^{\prime}\right)_{2}$ fragment (Alexa Fluor ${ }^{\circledR} 488$-conjugated) for $1 \mathrm{~h}$. Stained cells were mounted on a slide with ProLong Gold antifade reagent (Invitrogen, Grand Island, NY, USA) and fluorescence was determined under a Carl Zeiss LSM 710 confocal laser scanning microscope.

Statistical analysis. Data are presented as the mean \pm standard deviation for the indicated number of separate experiments. The mean of the control was compared with the mean of each individual treatment group by one-way ANOVA followed by Tukey's test using the statistical software SigmaPlot v.12.3
(Systat Software, Inc., San Jose, CA, USA), and a statistically significant difference was set at $\mathrm{p}<0.001$.

\section{Results}

Effects of S. serratifolium extracts on cell proliferation. To investigate the antiproliferative effects of three types of extracts, hexane, ethanol and ethyl acetate, from $S$. serratifolium, we performed WST-1 assay on human glioblastoma cancer U87MG, human cervical cancer HeLa, human gastric cancer MKN-28, human liver cancer SK-HEP 1 and noncancerous HEK293 cells following treatments with the extracts. As shown in Fig. 1, each extract had a cytotoxic effect on the human cancer cell lines. Among these extracts, the hexane extract from $S$. serratifolium (HES) exhibited the most effective inhibition of cell proliferation. HES particularly decreased the cell viability of the U87MG cells to a higher degree than that observed in the other cancer cell lines. The $\mathrm{IC}_{50}$ value of HES was observed between 14 and $16 \mu \mathrm{g} / \mathrm{ml}$ HES (Fig. 2). In addition, morphological cell changes were observed in a dose-dependent manner (Fig. 4A). However, there was no inhibitory effect on cell proliferation of the noncancerous HEK293 cells, indicating that HES particularly has antiproliferation effects on U87MG cells (Fig. 2B).

Antiproliferative effect of HES is mediated through the MAPK/ERK pathway. The MAPK/ERK cascade is closely 
$\mathbf{A}$

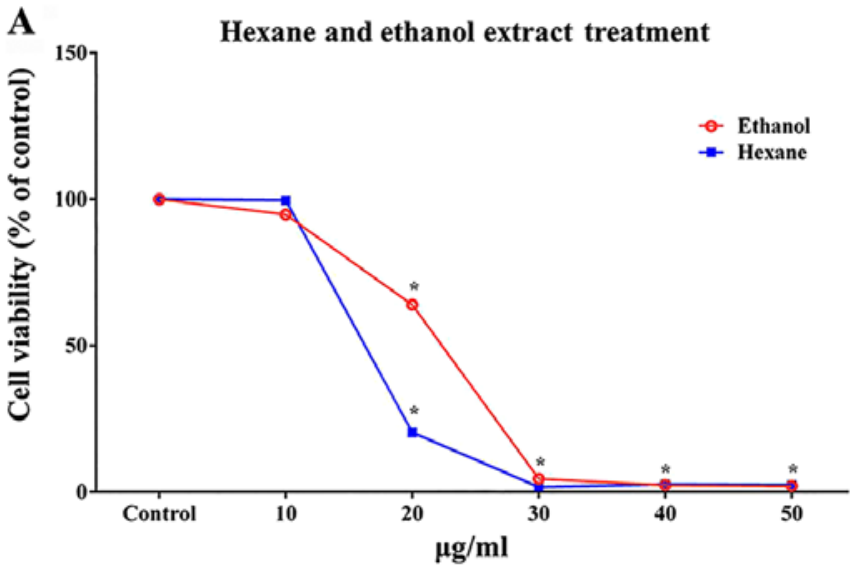

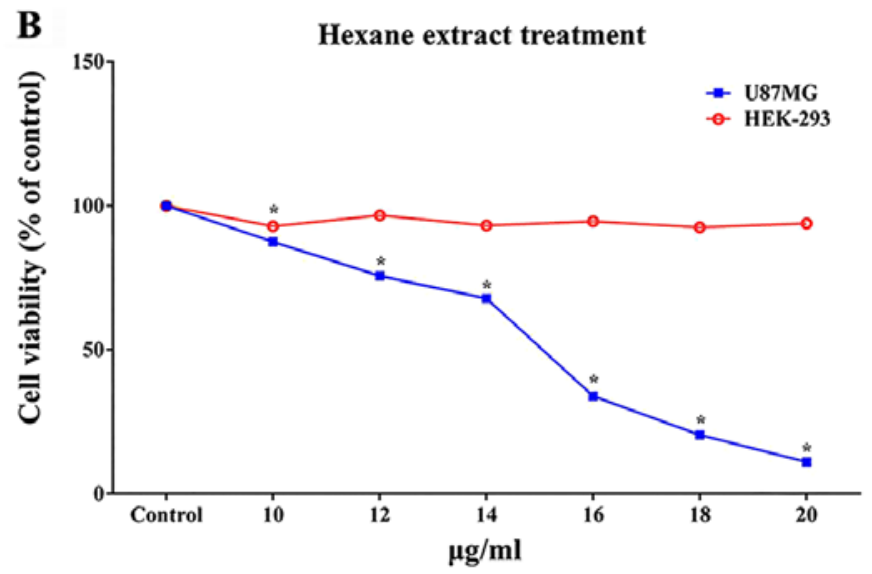

Figure 2. Antiproliferative effects of ethanol and hexane extracts from S. serratifolium on U87MG cells. (A) The hexane extract exhibited more effective inhibition of cell proliferation when compared with the ethanol extract. (B) HES had antiproliferative effects on U87MG cells, but did not affect the cell viability of non-cancerous HEK-293 cells. Each bar represents the mean \pm SD, $n=3$. * $p<0.001$, significant difference from the control by ANOVA. HES, hexane extract from Sargassum serratifolium.

A

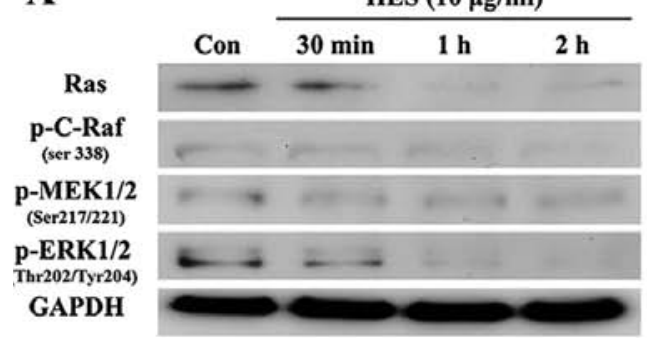

B
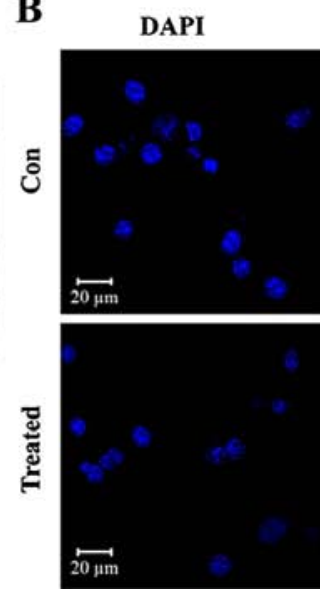

p-ERK
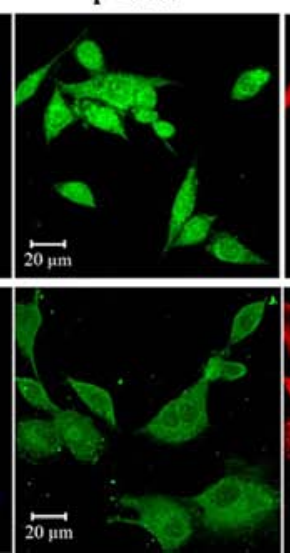

$\beta$-actin
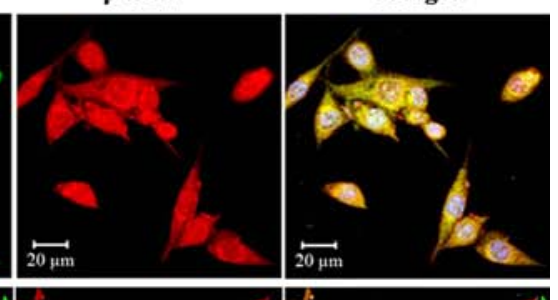

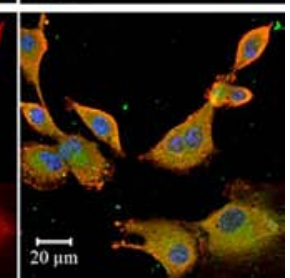

Figure 3. Effect of HES on downregulation of the MAPK/ERK pathway. (A) Expression of Ras and phosphorylation of C-Raf/MEK/ERK were detected by western blot analysis in the U87MG cells following treatment with $10 \mu \mathrm{g} / \mathrm{ml} \mathrm{HES} \mathrm{in} \mathrm{a} \mathrm{time-dependent} \mathrm{manner.} \mathrm{(B)} \mathrm{U87MG} \mathrm{cells} \mathrm{were} \mathrm{treated} \mathrm{with} \mathrm{HES,} \mathrm{and}$ examined by immunofluorescence staining to detect the level of phospho-ERK (green) and DAPI (nuclear; blue) and $\beta$-actin (cytoskeletal; red) using confocal laser scanning microscope. HES, hexane extract from Sargassum serratifolium.

related to activation of transcription factors and leads to cell proliferation. In the present study, we investigated the effect of HES on the MAPK/ERK pathway using western blot analysis. As shown in Fig. 3A, the expression of Ras and phosphorylation of C-Raf, MEK and ERK were downregulated by HES in a time-dependent manner. Furthermore, the expression level of phosphorylated ERK and translocation to the nucleus were also decreased by HES (Fig. 3B). Thus, our results indicated that HES suppressed cell proliferation via regulation of the MAPK/ERK pathway in U87MG cells.

Effect of HES on the degradation of the cytoskeleton. As HES induced morphological cell change (Fig. 4A), we hypothesized that the expression of cytoskeleton-related proteins may be affected by HES. Thus, we measured protein expression associated with actin dynamic signaling using western blot analysis. As shown in Fig. 4B, actin dynamic signaling, including integrin $\beta 1$, PI3K p110 $\alpha$, Rac, WAVE-2 and Arp-2, was decreased by HES in a dose-dependent manner. Therefore, these results showed that HES induced unstabilization of the cytoskeleton and affected cell survival through inactivation of actin dynamic signaling in U87MG cells.

HES inhibits the invasion and migration of U87MG cells. One of the most representative characteristics of glioblastoma is its invasive ability, diffusing into intact brain regions, which hinders elimination of the cancer by surgery (18). Thus, we investigated the inhibitory effects of HES on the metastatic ability of the U87MG cells. As shown in Fig. 5A, protein expression of MMP-2 and -9 was inhibited by HES in a dose-dependent manner. Additionally, wound healing assay results showed that the entire wound area in the HES-treated group was markedly decreased in comparison with the control group (Fig. 5B). In the Transwell invasion assay, the number of invasive cells was also decreased in a dose-dependent manner (Fig. 5C). Hence, our findings indicated that HES inhibited cell invasion and migration of U87MG cells via negative regulation of MMP-2 and -9 expression. 
A
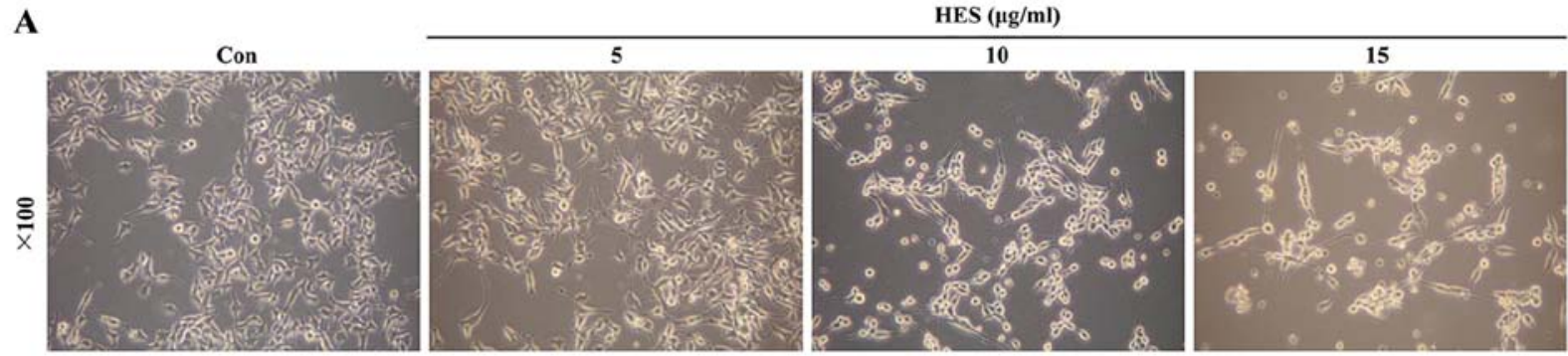

B

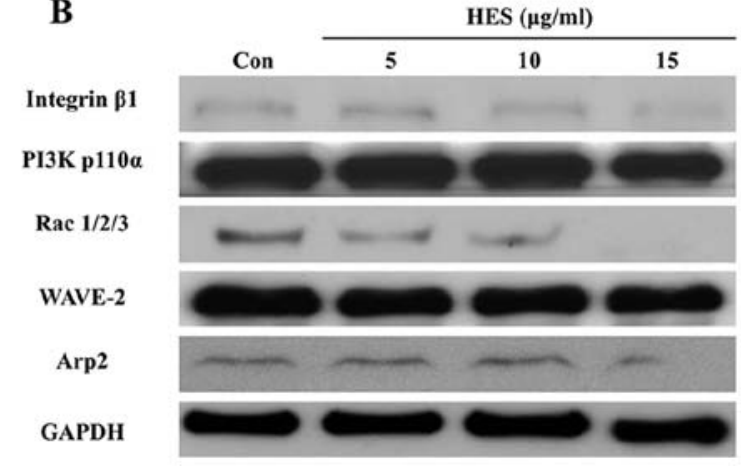

Figure 4. Effects of HES on morphological changes and actin dynamic signaling. (A) U87MG cells were treated with HES in a dose-dependent manner (0, 5 , 10 and $15 \mu \mathrm{g} / \mathrm{ml}$ ) for $24 \mathrm{~h}$, and the cell morphology was imaged under a phase contrast inverted microscope at a magnification of x100. (B) U87MG cells were treated with HES in a dose-dependent manner $(0,5,10$ and $15 \mu \mathrm{g} / \mathrm{ml})$ for $12 \mathrm{~h}$, and expression levels of proteins associated with actin dynamic signaling were detected by western blot analysis. HES, hexane extract from Sargassum serratifolium.

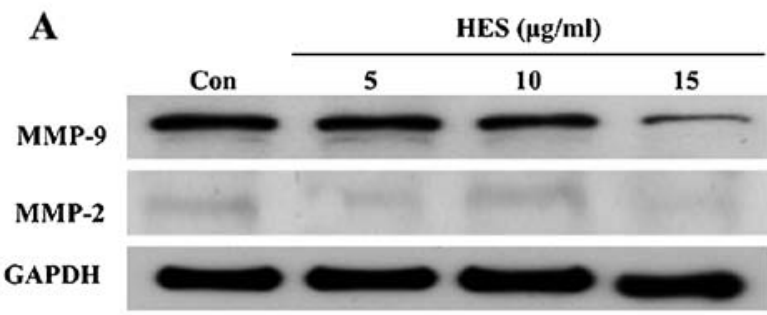

B

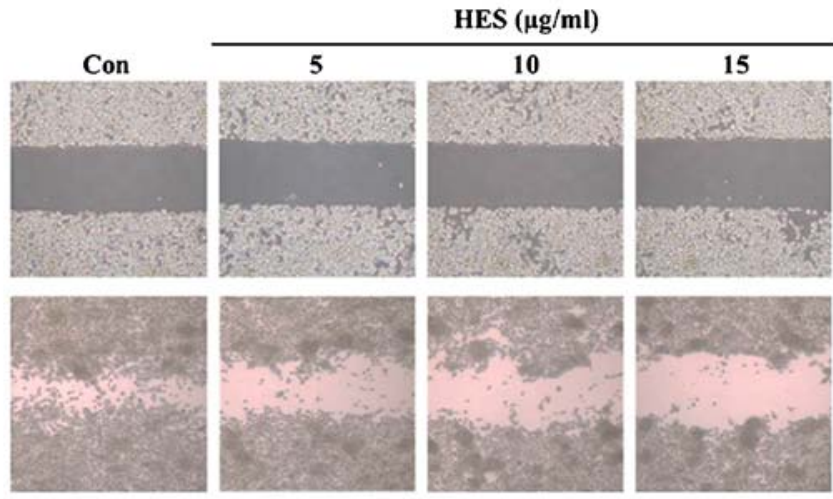

C
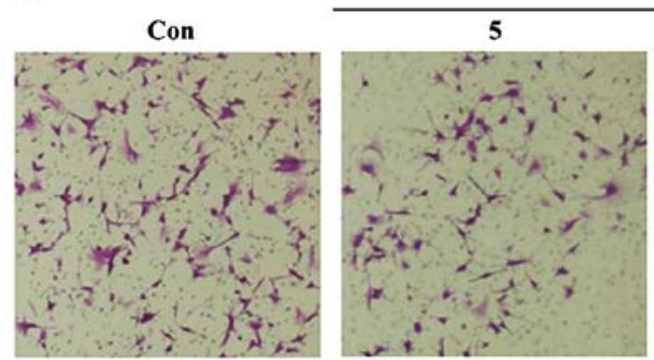

HES $(\mu \mathrm{g} / \mathrm{ml})$

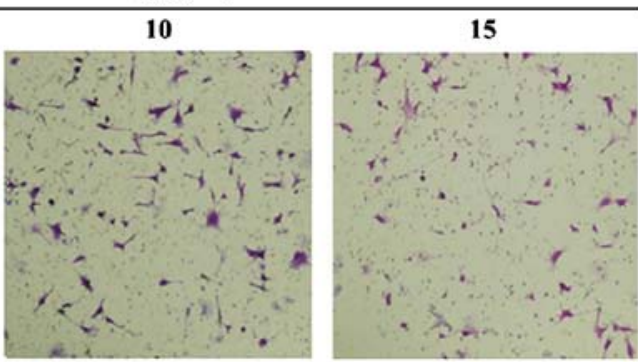

Figure 5. HES suppresses the cell migration and invasion of U87MG cells. (A) U87MG cells were treated with the indicated doses of HES for $24 \mathrm{~h}$. Western blot analysis of MMP-2 and -9 expression. (B) Wound healing and (C) Transwell invasion results showing the suppressive effects of HES on cell migration and invasion of U87MG cells at $24 \mathrm{~h}$ in a dose-dependent manner (magnification, $\mathrm{x} 40$ ). HES, hexane extract from Sargassum serratifolium. 


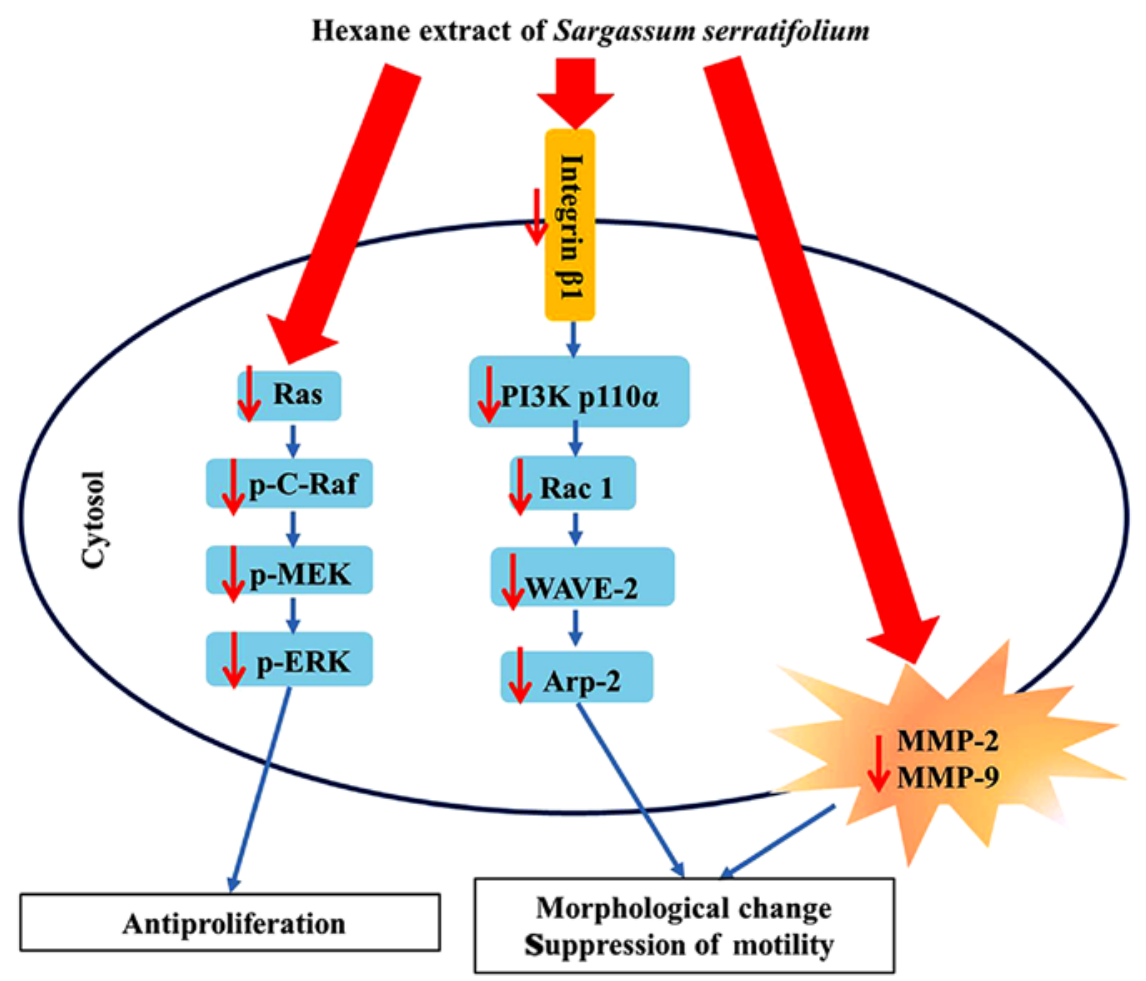

Figure 6. Schematic diagram indicating the anticancer signaling pathways mediated by HES in the U87MG cells. HES, hexane extract from Sargassum serratifolium.

\section{Discussion}

The present study is the first to demonstrate the anticancer potential of extracts from $S$. serratifolium. Among these extracts, a hexane extract from $S$. serratifolium (HES) sensitively induced inhibition of cell proliferation and morphological change in U87MG cells (Figs. 2B and 4A).

In glioblastoma, the Ras/Raf/MEK/ERK pathway is required for cell proliferation (18). Recently research has shown that various agents inhibiting this signaling pathway, such as sorafenib, an inhibitor of Raf, are able to inhibit proliferation and induce apoptosis in glioblastoma (20). This cascade signaling pathway is initiated by Ras activation, interacting with C-Raf and phosphorylating at serine (Ser) 338, tyrosine (Tyr) 341, threonine (Thr) 491 and Ser497 of C-Raf (21). Phosphorylated C-Raf directly activates MEK1 and MEK2, Tyr and Thr/Ser dual-specificity kinases, through phosphorylation at Ser217 and 221 (22). These kinases subsequently phosphorylate Thr202 and Tyr204 residues in p44/42 MAPK, ERK1/2, leading to phosphorylation of p90 ribosomal S6 kinase (p90RSK) which phosphorylates cAMP response element-binding protein (CREB) (23). ERK and CREB kinase phosphorylate transcription factors translocating to the nucleus for gene transcription (24). Our results demonstrated that the antiproliferative effects of HES were exerted by suppression of MAPK/ERK cascade signaling (Fig. 3).

The cytoskeleton is essential for morphological change, growth, survival, cell motility and cancer metastasis $(9,25)$. Hence, regulation of the cell cytoskeleton and morphological changes may be used to treat metastatic tumors (26). Actin dynamic signaling is one of the crucial signaling pathways for regulation of the cell cytoskeleton (27). This signaling is initiated by integrin $\beta 1$ which is located in the extracellular membrane and converts extracellular stimuli into intracellular signals (28). Integrin $\beta 1$ regulates expression of phosphoinositide 3-kinase (PI3K) p110 $\alpha$ and Rac $(29,30)$. Rac, Rho-family of small G proteins, regulates the cytoskeleton through activation of WAVE-2 leading to activation of Arp-2, consequently facilitating morphological change (31-33). This change regulates cytoskeletal stability, cell structure, cell motility and cell death $(34,35)$. Morphological change in the U87MG cells was observed following treatment with HES (Fig. 4A). Western blot analysis results also revealed that HES suppressed reorganization of the cytoskeleton through regulation of actin dynamic signaling, including integrin $\beta 1$, PI3K p110 $\alpha$, Rac1, WAVE-2 and Arp-2, resulting in inhibition of cell survival, growth and motility (Fig. 4B). Arp-2 and WAVE-2 are closely related to lamellipodium formation which regulates cell motility and invasion (36). In addition, degradation of the ECM by matrix metalloproteinases (MMPs) is required for the migration and invasion of metastatic cancer cells. MMPs, zinc-dependent endopeptidases, promote invasion and metastasis of cancer cells $(37,38)$. Among the members of the MMP family, MMP-2 and -9 are crucial for degradation of ECM (39). Therefore, western blot analysis, Transwell invasion and wound healing assays were performed to demonstrate the effects of HES on cell migration and invasion of the U87MG cells. As expected, the expression levels of MMP-2 and -9 were decreased in the glioblastoma cells following treatment with HES in a dose-dependent manner (Fig. 5A). Likewise, HES showed inhibitory effects on cell migration and invasion of the U87MG cells (Fig. 5B and C).

Taken together, the present study confirmed that HES has anticancer potential through regulation of the MAPK/ERK 
and actin dynamic pathways in human glioblastoma U87MG cells (Fig. 6). These findings demonstrated that HES may be used as a candidate anticancer agent for the treatment of human glioblastoma. To further analyze the detailed anticancer mechanisms of extracts from Sargarssuim serratifolium, we plan to use fractions of HES and investigate the effects of each fraction on glioblastoma.

\section{Acknowledgements}

The present study was supported by a Research Grant from KIOST-PKNU (Pukyong National University; 2015).

\section{References}

1. Black PM: Brain tumors. Part 1. N Engl J Med 324: 1471-1476, 1991.

2. Zaboronok A, Isobe T, Yamamoto T, Sato E, Takada K, Sakae T, Tsurushima $\mathrm{H}$ and Matsumura A: Proton beam irradiation stimulates migration and invasion of human U87 malignant glioma cells. J Radiat Res 55: 283-287, 2014.

3. Papi A, Bartolini G, Ammar K, Guerra F, Ferreri AM, Rocchi P and Orlandi M: Inhibitory effects of retinoic acid and IIF on growth, migration and invasiveness in the U87MG human glioblastoma cell line. Oncol Rep 18: 1015-1021, 2007.

4. Liebmann C: Regulation of MAP kinase activity by peptide receptor signalling pathway: Paradigms of multiplicity. Cell Signal 13: 777-785, 2001.

5. Bernards A and Settleman J: GAP control: Regulating the regulators of small GTPases. Trends Cell Biol 14: 377-385, 2004.

6. Blalock WL, Weinstein-Oppenheimer C, Chang F, Hoyle PE, Wang XY, Algate PA, Franklin RA, Oberhaus SM, Steelman LS and McCubrey JA: Signal transduction, cell cycle regulatory, and anti-apoptotic pathways regulated by IL-3 in hematopoietic cells: Possible sites for intervention with anti-neoplastic drugs. Leukemia 13: 1109-1166, 1999.

7. Xing J, Ginty DD and Greenberg ME: Coupling of the RAS-MAPK pathway to gene activation by RSK2, a growth factor-regulated CREB kinase. Science 273: 959-963, 1996.

8. Roux PP, Ballif BA, Anjum R, Gygi SP and Blenis J: Tumorpromoting phorbol esters and activated Ras inactivate the tuberous sclerosis tumor suppressor complex via p90 ribosomal S6 kinase. Proc Natl Acad Sci USA 101: 13489-13494, 2004.

9. Fletcher DA and Mullins RD: Cell mechanics and the cytoskeleton. Nature 463: 485-492, 2010.

10. Yamazaki D, Kurisu S and Takenawa T: Regulation of cancer cell motility through actin reorganization. Cancer Sci 96: 379-386, 2005.

11. Mullins RD: How WASP-family proteins and the Arp2/3 complex convert intracellular signals into cytoskeletal structures. Curr Opin Cell Biol 12: 91-96, 2000.

12. Wu C, Asokan SB, Berginski ME, Haynes EM, Sharpless NE, Griffith JD, Gomez SM and Bear JE: Arp2/3 is critical for lamellipodia and response to extracellular matrix cues but is dispensable for chemotaxis. Cell 148: 973-987, 2012.

13. Machesky LM: Lamellipodia and filopodia in metastasis and invasion. FEBS Lett 582: 2102-2111, 2008.

14. Curran S and Murray GI: Matrix metalloproteinases in tumour invasion and metastasis. J Pathol 189: 300-308, 1999.

15. Lin HH, Chen JH, Chou FP and Wang CJ: Protocatechuic acid inhibits cancer cell metastasis involving the down-regulation of Ras/Akt/NF- $\kappa \mathrm{B}$ pathway and MMP-2 production by targeting RhoB activation. Br J Pharmacol 162: 237-254, 2011.

16. Liu L, Heinrich M, Myers S and Dworjanyn SA: Towards a better understanding of medicinal uses of the brown seaweed Sargassum in Traditional Chinese Medicine: A phytochemical and pharmacological review. J Ethnopharmacol 142: 591-619, 2012 .

17. Huang GJ, Yang CM, Chang YS, Amagaya S, Wang HC, Hou WC, Huang SS and Hu ML: Hispolon suppresses SK-Hep1 human hepatoma cell metastasis by inhibiting matrix metalloproteinase-2/9 and urokinase-plasminogen activator through the PI3K/akt and ERK signaling pathways. J Agric Food Chem 58: 9468-9475, 2010.
18. Louis DN, Ohgaki H, Wiestler OD, Cavenee WK, Burger PC, Jouvet A, Scheithauer BW and Kleihues P: The 2007 WHO classification of tumours of the central nervous system. Acta Neuropathol 114: 97-109, 2007.

19. Clarke J, Butowski $\mathrm{N}$ and Chang S: Recent advances in therapy for glioblastoma. Arch Neurol 67: 279-283, 2010.

20. Carra E, Barbieri F, Marubbi D, Pattarozzi A, Favoni RE, Florio T and Daga A: Sorafenib selectively depletes human glioblastoma tumor-initiating cells from primary cultures. Cell Cycle 12: 491-500, 2013.

21. Chong H, Lee J and Guan KL: Positive and negative regulation of Raf kinase activity and function by phosphorylation. EMBO J 20: 3716-3727, 2001.

22. Alessi DR, Saito Y, Campbell DG, Cohen P, Sithanandam G, Rapp U, Ashworth A, Marshall CJ and Cowley S: Identification of the sites in MAP kinase kinase-1 phosphorylated by p74raf-1. EMBO J 13: 1610-1619, 1994.

23. Roberts PJ and Der CJ: Targeting the Raf-MEK-ERK mitogenactivated protein kinase cascade for the treatment of cancer. Oncogene 26: 3291-3310, 2007.

24. Bonni A, Brunet A, West AE, Datta SR, Takasu MA and Greenberg ME: Cell survival promoted by the Ras-MAPK signaling pathway by transcription-dependent and -independent mechanisms. Science 286: 1358-1362, 1999.

25. Colomba A and Ridley AJ: Analyzing the roles of Rho GTPases in cancer cell migration with a live cell imaging 3D-morphologybased assay. Methods Mol Biol 1120: 327-337, 2014.

26. Najm P and El-Sibai M: Palladin regulation of the actin structures needed for cancer invasion. Cell Adh Migr 8: 29-35, 2014.

27. Edwards KA, Demsky M, Montague RA, Weymouth N and Kiehart DP: GFP-moesin illuminates actin cytoskeleton dynamics in living tissue and demonstrates cell shape changes during morphogenesis in Drosophila. Dev Biol 191: 103-117, 1997.

28 Harburger DS and Calderwood DA: Integrin signalling at a glance. J Cell Sci 122: 159-163, 2009.

29. Miyamoto S, Teramoto H, Coso OA, Gutkind JS, Burbelo PD, Akiyama SK and Yamada KM: Integrin function: Molecular hierarchies of cytoskeletal and signaling molecules. J Cell Biol 131: 791-805, 1995.

30. Legate KR and Fässler R: Mechanisms that regulate adaptor binding to beta-integrin cytoplasmic tails. J Cell Sci 122: 187-198, 2009.

31. Etienne-Manneville S and Hall A: Rho GTPases in cell biology. Nature 420: 629-635, 2002

32. Kurisu S, Suetsugu S, YamazakiD, Yamaguchi H and Takenawa T: Rac-WAVE2 signaling is involved in the invasive and metastatic phenotypes of murine melanoma cells. Oncogene 24: 1309-1319, 2005.

33. Miki H, Suetsugu S and Takenawa T: WAVE, a novel WASPfamily protein involved in actin reorganization induced by Rac. EMBO J 17: 6932-6941, 1998.

34. Pollard TD and Cooper JA: Actin, a central player in cell shape and movement. Science 326: 1208-1212, 2009.

35. Wang F, Liu DZ, Xu H, Li Y, Wang W, Liu BL and Zhang LY: Thapsigargin induces apoptosis by impairing cytoskeleton dynamics in human lung adenocarcinoma cells. ScientificWorldJournal 2014: 619050, 2014.

36. Small JV, Stradal T, Vignal E and Rottner K: The lamellipodium: Where motility begins. Trends Cell Biol 12: 112-120, 2002.

37. Chen JH, Lin HH, Chiang TA, Hsu JD, Ho HH, Lee YC and Wang CJ: Gaseous nitrogen oxide promotes human lung cancer cell line A549 migration, invasion, and metastasis via iNOS-mediated MMP-2 production. Toxicol Sci 106: $364-375$, 2008.

38. Westermarck $\mathbf{J}$ and Kähäri VM: Regulation of matrix metalloproteinase expression in tumor invasion. FASEB J 13: 781-792, 1999.

39. Parks WC and Shapiro SD: Matrix metalloproteinases in lung biology. Respir Res 2: 10-19, 2001. 